\title{
El SALVADOREÑO Y LA FORMACIÓN DE OPINIÓN PÚBLICA EN EL CONTEXTO DE LA PRIMERA GUERRA FEDERAL CENTROAMERICANA, 1828-1829
}

\author{
El Salvadoreño and the Formation of the Public Opinion in the First \\ Federal War in Central America, 1828-1829
}

María Eugenia Claps-Arenas*

Resumen: En este artículo se aborda el estudio del periódico El Salvadoreño, atendiendo particularmente al uso que sus editores hicieron de algunos de los conceptos que fueron sustanciales en el ejercicio discursivo de los nuevos Estados hispanoamericanos, tales como revolución, aristocracia, pueblo, ciudadano y patriotismo, en el contexto de la primera guerra federal centroamericana (1826-1829). Destaca que uno de los objetivos del periódico era el de formar una opinión pública nacional favorable a los intereses salvadoreños en la citada contienda. Asimismo, se trata del rescate de un texto periódico poco conocido cuyo valor testimonial resulta relevante para el conocimiento de Centroamérica en aquellos años, en particular de El Salvador.

Palabras clave: El Salvadoreño, guerra federal, federalismo, centralismo, prensa, opinión pública.

Abstract: This paper focuses on the newspaper El Salvadoreño and its role in political discourse during the tumultuous years of the civil war in Central America between 1826 and 1829. Particular emphasis is given to the editorial board's use of concepts such as revolution, aristocracy, people, citizen, and patriotism, and to its goal of influencing public opinion regarding Salvadoran interests in the conflict. This review of El Salvadoreño also provides information regarding the aspirations and interests of Salvadorans during those years, while increasing our understanding of Central America and its people.

Keywords: El Salvadoreño, federal war, federalism, centralism, press, public opinion.

\footnotetext{
* María Eugenia Claps Arenas. Doctora en Historia por la Universidad de Alcalá, España. Profesora-investigadora en el Centro de Estudios Superiores de México y Centroamérica de la Universidad de Ciencias y Artes de Chiapas (CESMECA-UNICACH), México. Temas de especialización: hemerografía política centroamericana durante la República Federal de Centroamérica, 1824-1839. Correo electrónico: mariaeugenia.claps@unicach.mx. ORCID: 0000-0003-3889-3353.
}

Enviado a dictamen: 9 de mayo de 2018 Aprobación: 2 de octubre de 2018 Revisiones: 2 


\section{Introducción}

$\hat{E}$ ste es un trabajo que aborda una fuente hemerográfica como objeto de estudio, El Salvadoreño, y se centra en el discurso y la interpretación que sus editores hicieron de la realidad centroamericana que les ocupó, que fueron algunos meses de la primera guerra federal que afectó a la región entre septiembre de 1826 y abril de 1829.

En efecto, El Salvadoreño fue una publicación periódica que apareció el 5 de junio de 1828 y concluyó el 4 de enero de $1829,{ }^{1}$ salió dos veces por semana y se elaboró en la Imprenta del Estado, propiedad del gobierno, dirigida por el presbítero Miguel José Castro - quien se había desempeñado como editor de El Semanario Político y Mercantil de San Salvador, primer periódico del país - y por Gregorio Arévalo (Tenorio, 2006: 142).

Desde mi perspectiva, se puede considerar que este material tuvo el propósito de ser portavoz de El Salvador y de los salvadoreños en el contexto de la guerra civil. Así, sus artículos constituyen una importante interpretación de la época convulsa en que se produjeron y con ellos se buscó, entre otros objetivos, crear una opinión pública favorable a los intereses nacionales durante la citada contienda.

Ahora bien, vale la pena apuntar que en la época no se acostumbraba firmar los textos en las publicaciones periódicas, al menos en las que he revisado procedentes de España, México y Centroamérica. Confirmando esta regla, en los artículos de este periódico tampoco se encuentran rúbricas. Así, es probable que quienes fueron mencionados líneas arriba como directores de la Imprenta del Estado hayan sido autores de la gran mayoría de los artículos o, en todo caso, aprobaron el contenido que fue publicado. Puede también agregarse que Castro se opuso en su momento a la anexión del istmo centroamericano a México y defendió los ideales de la independencia (López Vallecillos, 1987: 67). De hecho, López Vallecillos (1987: 80) identifica como uno de los individuos que publicó en este periódico a José Matías Delgado. Este personaje fue un conocido político y religioso salvadoreño que destacó en esos años por sus gestiones destinadas a conseguir la autorización papal para la creación de un obispado en El Salvador.

Cabe mencionar también que en la capital del Estado salvadoreño circularon textos procedentes tanto de los otros Estados centroamericanos, como de México, Estados Unidos, Sudamérica y Europa, que fueron publicados en la prensa nacional. De esta forma, hay que considerar que la cultura impresa de las ciudades y Estados centroamericanos estaba profundamente conectada (Tenorio, 2006: 46).

Mi objetivo entonces fue el estudio de El Salvadoreño atendiendo especialmente a la idea y el uso que los editores hicieron de conceptos que formaron parte del discurso político del momento y que estuvieron estrechamente vinculados a la formación de los nuevos Estados nacionales en Hispanoamérica, así como de una opinión pública que les diera sustento. Las nociones conceptuales mencionadas en el material y que se analizan en este texto son las siguientes: revolución, aristocracia y familias aristocráticas, pueblo, ciudadano, guerra, paz, nación, patriotismo, federalismo, centralismo, independencia, soberanía, libertad de imprenta, elecciones y educación, conceptos que tuvieron que ver con el desenvolvimiento del Estado salvadoreño dentro de la federación centroamericana en el ámbito de la guerra federal. Mediante el análisis del uso de estos conceptos se intentó responder a las siguientes cuestiones: iqué posición manifestaron los editores frente al conflicto que se estaba viviendo en el istmo? y iqué expectativas existían sobre el desarrollo salvadoreño dentro de la federación en los meses en que circuló esta publicación? Todo esto en el entendido de que escribir periódicos implicaba en aquel entonces luchar por ganar credibilidad y abrirse un espacio en la contienda por el poder político (Tenorio, 2006: 103). Es decir, se trataba principalmente de una actividad política, por lo que es necesario considerar que la prensa constituyó un verdadero actor en el entorno histórico que le dio cabida, ya que fue elaborada por y dirigida a los sectores y grupos que tuvieron capacidad de decisión y acción a todo lo largo del siglo XIX en Centroamérica.

Es allí precisamente, en su efectividad política, en donde considero que está el impacto de estas 
publicaciones, no en la cantidad de lectores, que sin dudafueron escasos en una población mayoritariamente analfabeta y además en plena guerra civil durante estos años, sino en la posibilidad que tuvieron esos escasos lectores -entre quienes incluyo a los editores de otros periódicos en el istmo- de incidir políticamente en la dirección que tomaron los nuevos Estados.

Así, en mi opinión el material hemerográfico resulta una fuente de primera mano para conocer los debates ideológicos que caracterizaron aquellos años del devenir centroamericano, dado que fue una práctica común que los jefes de Estado y los dirigentes políticos en general auspiciaran la circulación de periódicos que apoyaron diferentes aspectos de su gestión, como sucedió con el presidente de la federación centroamericana Manuel José Arce (1825-1828) y el Diario de Guatemala (eneromarzo de 1828); o con el jefe político de Guatemala Mariano Gálvez y El Siglo de Lafayette (1831-1832), por poner sólo un par de ejemplos.

Es decir, en el presente trabajo propongo entender la prensa como un instrumento clave para hacer política, como una manera de hacerla e incluso como un protagonista de la lucha por el poder (Gantús y Salmerón, 2014: 14). ${ }^{2}$ No se trata, pues, solamente de un material hemerográfico que transmite ideas, sino que apela a la transformación, de manera que: "El valor de un escrito no se medirá ya sólo por su contenido veritativo, sino por su eficacia material para generar acciones" (Palti, 2008: 231). Debe considerar además que durante la mayor parte del siglo XIX los periódicos no iban dirigidos al pueblo, sino al público, es decir, al sector educado, y por lo tanto potencialmente dirigente de estas sociedades recién nacidas a la vida independiente (Mac Gowan, 1978). ${ }^{3}$

Asimismo, cabe señalar que uno de los objetivos que se buscaba en aquellos años de la reciente creación de los nuevos Estados hispanoamericanos era conseguir la formación de una opinión pública que diera lugar a la creación de sistemas republicanos de gobierno (Palti, 2008: 227). De esta manera, a partir de la lectura íntegra del material existente de este periódico, que se encuentra digitalizado en la colección de la página web de la Universidad Centroamericana de El Salvador (repositorio UCA), procuré identificar los conceptos a los que se ha hecho referencia para estudiar el tratamiento que se les dio, siempre teniendo en cuenta el contexto político salvadoreño del momento en el que se produjeron.

\section{Estado de la cuestión}

Son muy escasos los estudios acerca de la hemerografía centroamericana de la República federal, y los que existen se refieren por separado a los distintos Estados que conformaron la federación; básicamente se ocupan de Guatemala, El Salvador y Costa Rica.

Para el caso de Guatemala contamos con el trabajo de Catalina Barrios y Barrios (2003), Estudio histórico del periodismo guatemalteco (época colonial y siglo XIX), que es en realidad un amplio catálogo de las publicaciones que aparecieron en la época, donde no hay mayor análisis del contenido del material. En lo relativo a El Salvador, tenemos el importante texto de Ítalo López Vallecillos citado en este trabajo, El periodismo en El Salvador; donde el autor hizo un análisis muy interesante del contenido de algunos de los periódicos salvadoreños correspondientes al período de la República federal, pero sólo mencionó muy sucintamente al que ahora nos ocupa (López Vallecillos, 1987: 80). También existe el estudio de Tenorio Góchez (2006) sobre periódicos y cultura impresa en El Salvador entre 1824 y 1850. En esta obra la autora se centra en el contexto que dio lugar a las publicaciones salvadoreñas desde la creación de la federación en el istmo hasta el fin de la primera mitad del siglo XIX, y apunta lo siguiente:

La prensa nació en 1824 con el claro propósito de inscribir a San Salvador en el presente de la federación, de alcanzarle el estatus de ciudad con su propio obispo, de consolidar a sus hombres destacados como dirigentes con voz propia y lugar propio en las disputas por el quién decide, manda y determina rumbos para la nación centroamericana (Tenorio, 2006: 9). 
Por poner un ejemplo sobre Costa Rica, en su obra De la imprenta al periodismo. Los inicios de la comunicación impresa en Costa Rica, 1821-1850, Patricia Vega Jiménez (1995) emprendió un ejercicio de investigación histórica sometiendo las fuentes hemerográficas a nuevas preguntas, gracias a lo cual los interesados conocen mejor cómo eran y cómo funcionaban los talleres de impresión costarricenses, quiénes eran los lectores y colaboradores de los periódicos o cómo se distribuían y financiaban.

En cuanto al tema de la historia conceptual, ésta ha tenido importantes avances a partir de la publicación dirigida por Javier Fernández Sebastián (2009), Diccionario político y social del mundo iberoamericano. La era de las revoluciones, 1750-1850, que se ocupa de los iberconceptos abarcando vastas regiones como España, Portugal e Iberoamérica. En concreto, el caso de Centroamérica fue estudiado en el libro coordinado por Jordana Dym y Sajid Herrera sobre el vocabulario político en la región (2014), obra de particular importancia para el tema que nos ocupa. En ese sentido, el presente trabajo ha pretendido desentrañar el significado que se dio a los conceptos políticos que fueron manejados en El Salvadoreño, tomando en consideración los resultados obtenidos en ese relevante trabajo.

\section{Contexto histórico}

Antes de empezar con el análisis propuesto, es necesario considerar que el principio del federalismo comenzó a desarrollarse en Centroamérica en 1821, durante los debates que precedieron a la anexión a México, y fue defendido por los líderes de las provincias para terminar con el excesivo centralismo y la hegemonía de Guatemala. Cobró fuerza en 1823 tras el fin del Imperio de Agustín de Iturbide, y posteriormente quedó establecido como uno de los principios centrales de la Constitución de 1824 (Bonilla, 1999: 64).

De esta forma, la República federal se constituyó en Centroamérica entre 1823 y 1824, y se instauró formalmente en noviembre de ese último año. Más adelante, la primera guerra federal surgió entre actores que se aglutinaron en torno a los dos bandos ideológicos republicanos en pugna en ese entonces: centralistas y federalistas, o serviles — que en su mayoría habían sido realistas y partidarios del Imperio iturbidista- y fiebres - liberales radicales o exaltados - (Taracena, A., 2015b: 56). Asimismo, fue el resultado de la disputa de distintos grupos de poder por el control de los recursos para la supervivencia económica y política, y tuvo como principales protagonistas a los sectores dirigentes guatemaltecos y salvadoreños, los que con su exacerbado antagonismo de origen colonial dominaron la escena política centroamericana durante esos años (Taracena, A., 2015a: XIX). En efecto, la querella entre chapines y salvadoreños provenía del desacuerdo histórico entre los comerciantes exportadores guatemaltecos y los productores provincianos de insumos tan importantes para la economía de la región como el añil (Herrera, 2005).

Adicionalmente, puede establecerse que los federalistas consideraban que la soberanía recaía en los pueblos que conformaban los Estados federales, lo que implicaba una ampliación de la ciudadanía a los sectores populares urbanos, mientras que los centralistas estimaban que ésta debía concentrarse en los sectores cuyo estatus económico les había proporcionado educación suficiente como para hacerse cargo de las actividades administrativas y gubernamentales de los nuevos Estados (Taracena, A., 2015b: 58).

Ahora bien, la guerra federal puede fundamentarse en el complejo panorama creado tras las elecciones nacionales de abril de 1825 para elegir presidente de la federación, en las cuales quedó como triunfador Manuel José Arce, liberal símbolo de la resistencia salvadoreña, contra su contendiente José Cecilio del Valle, ilustrado hondureño de tendencia moderada radicado en Guatemala. Estas elecciones fueron consideradas dudosas al terminar con un resultado negociado, destinado a calmar las presiones de los exaltados guatemaltecos y salvadoreños, ya que se presumió una acción emprendida desde El Salvador contra el moderado y proguatemalteco Cecilio del Valle. Éste al final aceptó que fuera elegido Arce, acordando que el susodicho renunciara a que la diócesis 
de San Salvador fuera erigida obispado. Sin embargo, muchos desconocieron la autoridad federal de Arce, en especial las autoridades guatemaltecas.

Guatemala y los Estados coincidieron en sus esfuerzos por evitar que el gobierno federal se quedara con las rentas fiscales obtenidas por la producción de tabaco. Esto condujo al enfrentamiento abierto entre el gobierno guatemalteco y el federal encabezado por Arce. Este último disolvió al primero e impuso nuevas elecciones estatales por las cuales se formó un gobierno de guatemaltecos moderados aliados de Arce. Esta situación modificó el discurso salvadoreño gubernativo a favor de este último ya que se consideró que se acercaba a las aspiraciones hegemónicas de Guatemala, y lo preparó para una guerra contra el gobierno federal y el nuevo gobierno guatemalteco (Taracena, L.P., 2015: 9-10).

En suma, la constitucionalidad de los Estados federales y de la República federal no llegó a consolidarse pues se centró en la oposición de los primeros a ceder su soberanía al órgano federal. De allí derivaron las guerras, las rupturas y los alejamientos del pacto federal que culminaron en la intención de constituirse como repúblicas independientes. La unión también fue imposible porque las élites no pudieron construir intereses comunes; así, la fragmentación económica entre comerciantes y hacendados/ganaderos se convirtió en un obstáculo importante que no pudo ser superado (Taracena, L.P., 2015: 21).

Como apunta Sajid Herrera: "La historia de la federación estuvo entonces marcada por roces entre unos estados que defendieron su independencia fiscal, política y eclesiástica frente al fantasma del centralismo materializado en el poder federal, el cual dependía, según aquellos, de la odiada aristocracia guatemalteca" (Herrera, 2005: 914).

\section{El Salvadoreño y la formación de opinión pública}

Por las temáticas que aborda y teniendo en cuenta el panorama histórico reseñado líneas arriba, El Salvadoreño constituyó una de las expresiones más acabadas de los intereses de los sectores dirigentes salvadoreños durante la contienda federal y, entre otros objetivos, buscó formar una opinión pública que le fuera proclive.

Como se ha mencionado antes, la importancia de crear una opinión pública iba en función de la necesidad de constituir un nuevo principio de legitimación política para los Estados centroamericanos recién nacidos a la vida independiente. En todo caso, cabe apuntar que este concepto y los demás que aquí serán tratados se fueron desarrollando en el ámbito hispanoamericano desde la Ilustración, por lo menos, y que en cada etapa respondieron a los contextos, muy cambiantes en aquellos años de emancipación y de luchas internas en la búsqueda de consolidar un nuevo orden político: "En el período que se inicia entre 1825 a 1840 son los 'intelectuales orgánicos' quienes fomentan la identidad de la nación centroamericana, los que intentan resemantizar el concepto de 'opinión pública' para servir a su gran proyecto", el cual consistía en uniformar las opiniones políticas (Belaubre, 2014: 192). Uno de los vehículos que se utilizó entonces para ello fue la prensa.

Comenzando con el análisis del periódico que nos ocupa, en los primeros días de su aparición los editores expusieron claramente que mientras la guerra civil se prolongara, el principal objeto de sus páginas sería dar seguimiento a las medidas tomadas por el Supremo Gobierno del Estado de El Salvador para ajustar un convenio o tratado razonable con el representante del Ejecutivo Federal a efecto de alcanzar la paz en el área. ${ }^{4}$

En este sentido, por ejemplo, el periódico publicó las comunicaciones entre el Supremo Gobierno del Estado y Manuel Francisco Pavón — sobrino de Juan José de Aycinena- ${ }^{5}$ (Chandler, 1988: 6), enviado por el Ejecutivo Federal, que era en aquel momento el vicepresidente Mariano Beltranena, con el propósito de demostrar ante los lectores que el Estado salvadoreño procuraba sostener el sistema constitucional adoptado para el istmo. ${ }^{6}$

Ahora bien, la referida búsqueda del acuerdo y de la paz argumentada por los encargados de este periódico implica que no sea difícil ocuparse de los conceptos propuestos para el análisis, ya que fueron fundamentales en la creación de los nuevos Estados independientes de Hispanoamérica. Además, los editores demostraron 
un verdadero interés en la utilización propia de los conceptos, pues, tal y como apuntaron: "Una de las principales causas de nuestros errores proviene del equivocado sentido que damos a las palabras". ' Así, por ejemplo, se dieron a la tarea de explicar lo que debía entenderse por pueblo, por patriotismo, etcétera.

Ello no obstante, publicaron numerosos partes de guerra y comunicaciones entre la oficialidad, notas en las que procuraron destacar las victorias militares de los salvadoreños y de los otros Estados de la federación contra las armas guatemaltecas. Sin embargo, la situación bélica terminó por afectar de manera directa a esta publicación que dejó de circular un tiempo debido a: "Las urgentes atenciones de esta misma guerra [que] no nos han permitido concluir este primer trimestre"; empero, en la opinión de los editores la continuación de El Salvadoreño era importante por el servicio que brindaba al filósofo, al estadista y a todo hombre ilustrado o que aspiraba a serlo, pues informaba de los asuntos importantes de las naciones del mundo: ${ }^{9}$ "Aunque poco luminosos, nuestro periódico contribuye algún tanto a que los pueblos aprendan a conocer sus verdaderos intereses. A los pueblos nos dirigimos, a ellos es a quienes hemos hablado desde el principio, a ellos continuamos hablando"..$^{10}$ En estas palabras se encuentra un ejemplo de la aspiración de los encargados de este periódico en el sentido de contribuir a la formación de una opinión pública informada e ilustrada, particularmente necesaria en el contexto político que se presentaba en ese momento, en el que era fundamental defender con claridad los elementos fundadores del Estado salvadoreño independiente.

Sin embargo, finalmente la guerra y los escasos suscriptores provocaron que el periódico no pudiera sostener su aparición dos veces por semana a partir de mediados de agosto de 1828; desde esa fecha llegó a pasar más de un mes entre la publicación de un número y el siguiente, lo que determinó, a fin de cuentas, lo que parece ser su desaparición definitiva en enero de 1829.

Otro aspecto importante de señalar es que entre las publicaciones que nutrieron a la que ahora nos ocupa estuvieron las revistas editadas en Londres por Rudolph Ackermann para el público hispanoamericano, material que fue elaborado por el español liberal José Joaquín de Mora, a la sazón exiliado en Inglaterra y residente en Londres. Éstas fueron: el Museo Universal de Ciencias y Artes, y el Correo Literario y Político de Londres. Como veremos, las definiciones de algunos de los conceptos que se analizarán fueron tomadas directamente de estas publicaciones. Cabe aquí agregar que el editor Ackermann en esos años instaló establecimientos en las principales capitales hispanoamericanas, incluyendo Guatemala, en los que se vendían las citadas revistas, así como catecismos y una amplia variedad de obras didácticas y literarias, por ello su adquisición fue posible en Centroamérica.

Para abordar los conceptos antes señalados seguí el orden en el que aparecen en El Salvadoreño, pues forman parte del discurso que en él encontramos, y están naturalmente vinculados en la argumentación de los editores. En este sentido, en cuanto al concepto "revolución", el primer artículo del periódico está dedicado al "Origen de la revolución actual", es decir, de la guerra civil que asolaba la región en esos momentos, la cual fue atribuida en sus páginas a la aristocracia guatemalteca, sector que, de acuerdo con los editores, no estaba conforme con el sistema federativo y buscaba el centralismo, pues era más propicio a la preservación de sus intereses como grupo social privilegiado. Así, en ese apartado los autores propusieron que la revolución que se estaba viviendo no era obra del pueblo contra las nuevas instituciones ni de los jefes de los Estados, sino de la aristocracia de Guatemala, combinada con la de toda la república centroamericana, contra el régimen establecido." Así, pues, no se trataba de un movimiento popular mayoritario, sino de un intento de las élites guatemaltecas por mantener una situación de privilegio.

Ahora bien, siguiendo con la argumentación utilizada en el periódico, el modus operandi de dicho sector consistió en apoyar la elección de un presidente federal que le fuera proclive, y lo encontró en la persona de Manuel José Arce, de tal manera que cuando el Congreso pidió al Ejecutivo la distribución de las rentas públicas, éste se negó aduciendo "pretextos frívolos", con lo que quebrantó la ley. Entonces varios diputados renunciaron, lo que dio como resultado que el Congreso 
se disolviera, y otro tanto sucedió con el Senado, lo que dio inicio a la guerra civil. Se observa entonces que la línea del periódico que nos ocupa fue expresamente contraria al presidente Arce, a quien se responsabilizó de la situación bélica.

En la interpretación de los editores, el ejecutivo convocó a un congreso anticonstitucional en todos los aspectos, ${ }^{12}$ destruyó la división de poderes, se atribuyó la soberanía de la nación, aniquiló la representación nacional y desorganizó al Estado de Guatemala; entonces hizo su aparición la "horrible cabeza de la aristocracia" representada por Mariano Aycinena. ${ }^{13}$ Otro atentado contra la Constitución fue la promulgación de una ley que prohibía a los Estados contratar empréstitos sobre el crédito de sus propias rentas, así como la destrucción de la milicia cívica de Guatemala y de El Salvador. ${ }^{14}$

En la continuación de este artículo se afirma que la aristocracia guatemalteca quería gobernar por sí sola sometiendo a los Estados del istmo a su antigua condición de provincias de Guatemala; es decir, existía una gran desconfianza respecto de los grupos dirigentes de la otrora capital del reino. Así, los responsables del texto que nos ocupa agregaron que los aristócratas guatemaltecos aspiraban a tener en sus manos las rentas públicas y a imponer a su arbitrio contribuciones, empréstitos y todo tipo de exacciones, además de a controlar los puertos y el comercio para llenar de riquezas a Guatemala y colmar de miserias a las provincias. Por otra parte, tampoco existiría libertad de expresión, ya que la imprenta se utilizaría únicamente para el elogio de los opresores. En suma, sometidos a la nobleza chapina se volvería en Centroamérica a la época feudal, ${ }^{15}$ por ello, los Estados del istmo debían oponerse a que tuvieran efecto los fines y objetivos con que había sido promovida la revolución. Posteriormente, los editores abundaron en esta idea apuntando lo siguiente: "Desde el principio han manifestado sus autores el designio de abolir la constitución fundamental de la república, de aniquilar la soberanía e independencia de los estados y de sistemar [sic] su administración al modo en que lo estaba en los tiempos oscuros del régimen colonial". ${ }^{16}$
Es decir, siguiendo con la argumentación presentada en El Salvadoreño, las familias aristócratas guatemaltecas y el propio Estado de Guatemala aspiraban a establecer el centralismo en detrimento de la implementación en el istmo de un verdadero sistema federal que respetara la autonomía del resto de los países del área en los aspectos económico, político y militar. En este sentido es preciso apuntar que, de acuerdo con algunos autores contemporáneos, en el entendimiento de los salvadoreños del siglo XIX la federación o unión centroamericana debía ser un proceso liderado por ellos, y no implicar el riesgo de caer bajo la hegemonía guatemalteca; así, una parte de la élite salvadoreña decimonónica apoyó la federación por la poca confianza que tenían en el desarrollo del país como Estado independiente (López Bernal, 2011: 76-77), esto mientras los centralistas estaban aglutinados en torno a los conservadores guatemaltecos (Taracena, A., 1995: 49).

En todo caso, vale la pena subrayar que, tal y como se deduce por el discurso de este periódico, la continua oposición a la "aristocracia" guatemalteca, y a los centralistas, generó entre los sectores dirigentes de El Salvador un proceso de construcción de su identidad política (Herrera, 2005: 914).

Haciendo un repaso histórico, los encargados de El Salvadoreño reflexionaron en torno a que las familias nobles chapinas fueron las primeras en incidir para lograr la independencia política de la región respecto de España, pero agregaron que lo hicieron con el objeto de apoderarse "absolutamente" de la nación. Después, y contra la voluntad de El Salvador, se sometieron al emperador mexicano Agustín de Iturbide, representante de la aristocracia de ese país, y tras su abdicación pensaron en aniquilar la representación nacional, desorganizar a los Estados y subvertir todo el orden federativo para dominar en Centroamérica. ${ }^{17}$ Todos estos objetivos fueron alcanzados fácilmente en Guatemala, en donde el fanatismo y la ignorancia en que procuraban mantener al pueblo les confirieron un poder arbitrario, con el que por ejemplo destruyeron el Congreso y el Senado, así como a las autoridades legítimas del Estado para colocar en su lugar a los “Aycinenas," los "Beltranenas" y los "Montúfares". Pero 
San Salvador siempre se había opuesto a sus miras y juró una constitución conveniente a sus intereses, por lo que los salvadoreños fueron calificados como anarquistas, ${ }^{18}$ mientras que Honduras, Nicaragua y Costa Rica hicieron lo mismo en lo relativo a establecer su propio orden constitucional. Así, en El Salvadoreño, además de involucrar a los otros Estados que formaban la república centroamericana en su oposición a los designios de lo que identificaron como las familias aristócratas de Guatemala - que los atacaban a ellos de la misma manera que a los hondureños y nicaragüenses-, dieron a éstas un consejo: "Desistid de la loca empresa que habeis [sic] comenzado, volved la libertad que habeis [sic] usurpado a Guatemala; dejad tranquilos a los estados [...] no querais [sic] pesar sobre la clase más numerosa y apreciable de la sociedad [...]". 19

Ahora bien, en lo relativo a la definición de la palabra "pueblo", los encargados del material apuntaron que éste se constituía por la universalidad de los ciudadanos. Sin embargo, cabe indicar que en esa época el concepto de "ciudadano" se refería a la minoría civil y militar con solvencia económica y que podía expresarse en las elecciones; es decir, el término señalaba sólo al sector educado y pudiente de la población (Taracena, A., 1995: 47). En tal dirección, esta publicación propuso que el pueblo era la nación cuya voluntad se expresaba a través de las leyes. Por lo tanto, el pueblo de Centroamérica no residía en Guatemala ni en San Vicente ni en León, no era equivalente a la clase militar ni a ninguna otra, era en cambio la "reunión de los centroamericanos". ${ }^{20}$

Abundando en este tema, el concepto "pueblo" tuvo en el siglo XIX múltiples significados. A partir de 1808 en el ámbito hispanoamericano se le confirió al pueblo el principio de legitimidad en tanto era el titular de la soberanía (Gutiérrez, 2014: 25l; López Bernal, 2011: 68), y en este sentido el término fue usado en el periódico que nos ocupa, donde los editores agregaron que los pueblos se manifestaban durante las elecciones ejerciendo un derecho que les era inherente para practicar su soberanía. Así, en su opinión, los escritores que reconocieron el principio de la soberanía nacional y los legisladores que la sancionaron habían procurado establecer reglas para que las elecciones fueran la libre expresión de la voluntad general. Y aunque a veces esta última pudiera beneficiar a individuos poco aptos, ambiciosos y corruptos, la experiencia que se había vivido en Centroamérica seguramente determinaría que los ciudadanos fueran en el futuro más cuidadosos en sus decisiones al momento de emitir su voto. ${ }^{21}$

Es interesante que los editores realizaran esta reflexión sobre las elecciones, la cual coincide con la opinión de algunos autores acerca de que la prensa escrita salvadoreña tuvo durante el siglo XIX un protagonismo importante en esos procesos, ya que contribuyó a la formación de una opinión pública, generó debates y polémicas entre los grupos políticos e incluso movilizó a los votantes (Herrera, 2011: 178).

En un sistema como el republicano federal que habían adoptado los Estados del istmo, el pueblo delegaba su representación en el Congreso y era el único que podía cambiar una ley constitucional, por eso las medidas tomadas por Arce en diciembre de 1827 convocando un nuevo constituyente fueron consideradas atentatorias a la Constitución por los editores de El Salvadoreño.

Sin embargo, como un medio de conseguir la tan ansiada paz en la región, apuntaron que, si bien no les parecía una medida del todo legítima, aprobaban que en las negociaciones entre el Ejecutivo federal y el gobierno salvadoreño, este último hubiera terminado por aceptar la renovación total de los individuos que formaban el Congreso y el Senado como el único medio de alcanzarla, tal y como había propuesto el presidente Arce en su decreto del 5 de diciembre de $1827 .{ }^{22}$ Esto era imprescindible, afirmaron, puesto que durante las revoluciones no existía la posibilidad de que las naciones operasen de acuerdo con las leyes y con un Estado de derecho, y El Salvador había sufrido muchas pérdidas por una guerra que era urgente concluir.

Ello no obstante, se produjeron hechos que dificultaron enormemente la consecución de la paz en el istmo, como fue el asesinato del colombiano Rafael Merino, general en jefe de las armas de El Salvador, acaecido el 13 de junio de 1828. En la interpretación de los responsables de El Salvadoreño, dicho crimen, 
perpetrado por el "abominable chapetón (o español)" Vicente Domínguez — quien según su opinión estaba al servicio de Aycinena-, fue fraguado por las familias aristocráticas de Guatemala, quienes habían: "desahogado su injusto resentimiento y satisfecho su odioso rencor sacrificando al benemérito general Merino [...] quien había empleado sus días en luchar contra los españoles"; ${ }^{23}$ agregaron que su delito fue apoyar la causa de El Salvador, con lo que sostuvo la constitución jurada por el pueblo y rechazó los asaltos del poder arbitrario procedentes de la antigua capital centroamericana.

Los editores consideraron que el principal infractor de las leyes no había sido Merino, como adujeron sus asesinos, sino el vicepresidente guatemalteco Mariano Beltranena, que mandaba ese país y pretendía apoderarse de todos los Estados del istmo: "Bajo los nombres sacrosantos de Constitución (y) Federación, se hace la guerra a los pueblos de la república por las familias de Guatemala, (que) ni respetan, ni aman la Constitución, ni existe tal régimen federativo". ${ }^{24}$

Sin embargo, cabe apuntar que, de acuerdo con un artículo de Arturo Taracena, Merino había sido despojado del mando por el propio gobierno salvadoreño a fines de abril de 1828 debido a sus aparatosas derrotas en el campo de batalla, y había pedido pasaporte para retornar a su natal Colombia, cosa que trató de hacer en el navío Caupolicán, pero al llegar al puerto de La Unión fue hecho prisionero por el coronel Domínguez, y luego fue pasado por las armas sin que mediara juicio alguno (Taracena, A., 2010).

De cualquier manera, lo que quisiera destacar es que los editores de El Salvadoreño utilizaron el fusilamiento de Merino para atacar con dureza a las autoridades guatemaltecas, particularmente a las denominadas "familias aristocráticas", enemigas en su concepto del orden republicano federal que se había adoptado en el istmo. Lo anterior ocurría mientras que, en sus palabras, los Estados de El Salvador, Honduras, Nicaragua y Costa Rica tenían por divisa "federación o muerte", odio a las familias de Guatemala, exterminio de todo tirano, muerte a la aristocracia, libertad, igualdad legal y justicia. ${ }^{25}$
Asimismo, se observa en las páginas del material hemerográfico que nos ocupa la vinculación entre las familias "nobles" chapinas y las españolas, pues en su concepto lo que pretendían las primeras era retornar al dominio ibérico o aliarse con los peninsulares contra la república centroamericana, por lo que también se les denominó "godo aristócratas".

Para argumentar más esta simbiosis, los editores salvadoreños apuntaron que las familias chapinas habían procurado imitar al partido borbonista mexicano, ya que tenían un órgano informativo titulado El Indicador, que era copia de El Sol, periódico mexicano en el que, de acuerdo con su interpretación, los borbonistas de dicha nación, como Lucas Alamán, exponían los postulados borbónicos y apoyaban a la madre patria en sus aspiraciones respecto de la Hispanoamérica recién emancipada. ${ }^{26}$ En este punto, es oportuno destacar el conocimiento que se tenía en El Salvador, así como en Centroamérica en general, de las publicaciones periódicas mexicanas, fenómeno por el cual ciertamente esta publicación fue utilizada para dar una interpretación a situaciones como la que acaba de ser reseñada.

Ahora bien, de acuerdo con los encargados de El Salvadoreño, en Guatemala se debería seguir el loable ejemplo de los mexicanos que no eran borbonistas, como los que ordenaron el fusilamiento del fraile español Joaquín Arenas porque pretendía organizar el regreso de México al dominio colonial, ${ }^{27}$ y decretaron la llamada Ley de Empleos por la que se prohibía que los españoles conservaran puestos gubernamentales. ${ }^{28}$ Esto, expusieron los editores salvadoreños, mientras que en Guatemala se había fusilado a militares americanos, como el citado Merino, y donde en general se estimaba a los españoles, quienes seguían teniendo una gran influencia en los negocios públicos de ese país. ${ }^{29}$

En todo caso, los sucesos que se desarrollaban en México fueron especialmente atendidos en el periódico salvadoreño, por ejemplo las elecciones para presidente de la república que tuvieron lugar en dicha nación en 1828. Los editores fueron partidarios de Vicente Guerrero, caracterizado en sus páginas como el padre de los pueblos y el héroe del sur, mientras 
que el otro contendiente, Manuel Gómez Pedraza, fue presentado como un escocés corrupto e intrigante, que había distribuido dinero para que las legislaturas de los Estados sufragaran por él..$^{30}$ Llama la atención el interés demostrado por la situación mexicana, que es reseñada a partir del periódico El Águila Mexicana. Es clara la preferencia de los editores salvadoreños por el grupo político que en México se conoció en esos años como los yorkinos, opuestos al sector moderado, también denominado escocés, acusados por los primeros de ser proespañoles. A partir de lo anterior se observa una coincidencia política importante entre los yorkinos mexicanos y los editores de este periódico en lo que respecta a la forma de concebir a los españoles residentes en estos países, que fueron vistos como los enemigos potenciales para la conservación de la independencia. Es decir, México fue una referencia para los políticos centroamericanos, como lo demuestran las referencias y comparaciones mencionadas.

Volviendo al istmo, lo que sucedía en Guatemala fue contrastado en el periódico centroamericano que nos ocupa con lo que acontecía en El Salvador, país que, de acuerdo con la interpretación de los editores, se había destacado por constituirse en asilo de la libertad en el istmo, ya que, por ejemplo, en 1811 se llevó a cabo aquello que denominaron "el primer grito de la independencia", quefue "sofocado por el guatemalteco José de Aycinena". En suma, la reflexión que se encuentra en este artículo apunta a que las familias guatemaltecas fueron en todos los tiempos enemigas de El Salvador, y que en aquellos momentos estaban unidas a los españoles para entregar Centroamérica a Fernando VII, ya que por sí solos no podían dominar a los salvadoreños. ${ }^{31}$

Por otra parte, quizá como una forma de justificar la continuación de las hostilidades, también encontramos en El Salvadoreño el desarrollo del concepto de "patriotismo", que fue presentado como la legítima defensa de los intereses de la provincia, república o sociedad más inmediata del individuo, pero sobre todo: "Lo que caracteriza al verdadero patriotismo es su odio a la injusticia y a toda clase de arbitrariedad o tiranía", ${ }^{32}$ esto último en clara referencia a las familias aristocráticas de Guatemala. En todo caso, para ese momento, julio de 1828 , en este periódico ya se descartaba la posibilidad de alcanzar la paz en la región, y se encuentra más bien la expresión de ideas como la siguiente: “[...] la guerra civil produce mil bienes, una vez se ha hecho necesaria como la nuestra, para conservar las leyes patrias y la independencia de la nación". ${ }^{33}$

En cuanto al concepto de "libertad de imprenta", los editores la consideraron un elemento indispensable para el adelanto de la civilización. ${ }^{34}$ Retomando las ideas de José Joaquín de Mora vertidas en las revistas londinenses antes referidas, resumieron las ventajas de dicho invento, que divulgaba el conocimiento y en consecuencia transformaba positivamente los hábitos y las opiniones, generando con ello el bienestar de los pueblos al destruir el error y las tinieblas de la ignorancia. ${ }^{35}$ Asimismo, la ilustración debía comprender a todos los ciudadanos ayudándose de la imprenta para generalizar el conocimiento. ${ }^{36}$ Así, elemento indispensable de la educación era el uso de la imprenta para difundirla y conseguir el óptimo desarrollo de las naciones.

Adicionalmente, en El Salvadoreño se propuso la difusión del conocimiento a través del uso de los catecismos que el editor Rudolph Ackermann había elaborado para Hispanoamérica, material que fue ampliamente recomendado por José Joaquín de Mora en la revista Museo Universal de Ciencias y Artes. De esta manera, al desarrollar el tema de la enseñanza para los nuevos Estados hispanoamericanos, los editores salvadoreños recurrieron a la mencionada revista londinense y a las ideas de su principal editor, en el sentido de que el método interrogativo utilizado en los catecismos — preguntas y respuestas - era el más económico para el rápido aprendizaje de nociones fundamentales en los nacientes Estados americanos, ya que a través de su estudio el ciudadano aprendía a someterse a las leyes y a obedecer a las autoridades legítimamente establecidas, además de a adquirir los hábitos de orden y moderación: "El sistema interrogativo adoptado en todos los establecimientos de educación de Inglaterra, es una de las mejoras más importantes que se han introducido hasta ahora en la enseñanza pública" ${ }^{37}$ 
Siguiendo con el material tomado del Museo, en las páginas de El Salvadoreño se halla un artículo muy optimista sobre lo que significaba la independencia de la América antes española; en él se vislumbraban las mejores expectativas para un área que sólo había ganado tras su emancipación política de la otrora madre patria, ya que a partir de dicho proceso se había avanzado enormemente en ilustración, en comercio y en todos los órdenes de gobierno. ${ }^{38}$

Vale la pena mencionar la importancia que tuvo en esos años la producción editorial de Ackermann para la Hispanoamérica recién emancipada. Dicho editor encabezó toda una empresa de producción literaria que comprendió, como se ha mencionado, revistas, catecismos, diccionarios, traducciones de clásicos, obras inéditas de historia, economía política y literatura, así como ilustraciones gráficas, calendarios y todo tipo de novedades para el público hispanoamericano, que había quedado huérfano de producciones de esos tipos tras su independencia política de España. Lo interesante es que los encargados de elaborar los textos fueron los españoles liberales entonces exiliados en Inglaterra que vivían en Londres, sede de esa producción editorial. La emigración de personas de excelente preparación académica, muchas de ellas profesionales, coincidió con el establecimiento en Francia e Inglaterra de empresas editoriales que tenían puesta su mira en los recién liberados países americanos de habla española, donde se abría un nuevo mercado de libros (Llorens, 1954, citado en Claps, 1999: 6).

Para lograr su cometido de manera más efectiva, Ackermann estableció librerías en las principales capitales americanas, así como en algunos puertos de importancia, entre los que pueden citarse la Ciudad de México, Guatemala, Lima, Buenos Aires o Valparaíso.

Como hemos visto, dos de las revistas de Ackermann, elaboradas por el español José Joaquín de Mora, fueron citadas y utilizadas por los editores de El Salvadoreño para respaldar y argumentar sus propuestas, de allí la importancia que adquirió este material y la necesidad de referirse a él en este trabajo.

\section{Conclusiones}

A manera de conclusión se pueden establecer los siguientes puntos. Los artículos de El Salvadoreño muestran que en un primer momento sus editores, y en general la clase política del país representada por ellos, creyeron en la posibilidad de terminar con la guerra civil que se desarrollaba entonces en el istmo, equiparada en sus páginas a una revolución auspiciada por las élites guatemaltecas para acabar con el sistema federal centroamericano, y por ello anunciaron que el gobierno de El Salvador estaba dispuesto a secundar el llamado a un nuevo Congreso propuesto por el presidente federal. Sin embargo, la situación se fue complicando en el contexto bélico, y el fusilamiento de Rafael Merino, quien se había desempeñado como general en jefe de las armas salvadoreñas, fue utilizado como argumento para justificar la continuación de las hostilidades. A partir de entonces, el discurso que se encuentra en el periódico incentiva el patriotismo como una estrategia legítima para seguir la lucha contra el enemigo, es decir, Guatemala y las familias aristocráticas que encabezaban su gobierno.

Así, encontramos que la propuesta de este periódico consistía en arremeter contra Guatemala y lo que se consideraba como sus afanes centralistas e incluso proespañoles ya que, de acuerdo con la interpretación de los editores, los chapines habían demostrado que no estaban dispuestos a respetar un régimen federal como el que regía entonces en Centroamérica, y buscaban establecer un sistema centralista que les permitiera seguir siendo los líderes en la región, o en su defecto volver al dominio español que tanto les había favorecido. De todas formas, no se puede soslayar la velada aspiración de El Salvador de encabezar la federación centroamericana, tal y como han sugerido algunos autores (López Bernal, 2011).

En este contexto, los editores fueron desarrollando los conceptos examinados dentro del discurso político que propusieron, uno de cuyos objetivos era la formación de una opinión pública favorable a los intereses salvadoreños en la contienda y en el propio sistema 
republicano federal adoptado en Centroamérica, como lo demuestra la afirmación citada en este trabajo relativa a la necesidad de que El Salvadoreño continuara circulando para formar e informar a los lectores. ${ }^{39}$ Así, los encargados del periódico abordaron conceptos como el de revolución o el de guerra civil — que imperaba en la zona y de la que responsabilizaron a los aristócratas guatemaltecos-; el de pueblo, al que identificaron como la base ciudadana con derecho a voto en un sistema constitucional; los de nación y patriotismo, porque debían enarbolar la defensa de los derechos de El Salvador frente a los demás gobiernos que formaban el istmo; y los de federalismo y centralismo, afirmando que los verdaderos federalistas eran los salvadoreños, los hondureños, los nicaragüenses y los costarricenses, que se oponían a las aspiraciones centralistas y proespañolas de los guatemaltecos.

También se encontró que México fue un referente importante para los políticos centroamericanos de la época, ya que los editores del periódico utilizaron la historia y el devenir mexicano como Estado independiente a manera de ejemplo tanto de lo que se debía emular, como de aquello que había que evitar, esto a partir de publicaciones periódicas mexicanas que conocían bien como El Sol y El Águila Mexicana.

Por último, vale la pena reflexionar en torno a las cuestiones educativas, así como al material utilizado para ocuparse de este tema. La educación fue concebida como el proceso fundamental para el desarrollo óptimo de los nuevos ciudadanos, y en este sentido los editores utilizaron las obras editadas por Rudolph Ackermann desde la capital inglesa, como las revistas literarias y científicas el Museo Universal de Ciencias y Artes y el Correo Literario y Político de Londres, ambas elaboradas por el liberal español José Joaquín de Mora, es decir, la influencia española seguía presente en esa época a partir del pensamiento de los españoles liberales refugiados en Inglaterra. Asimismo, se recomendó el uso de los catecismos y del sistema lancasteriano, propuestos como la mejor forma de educar a los nuevos ciudadanos hispanoamericanos.

Finalmente, debido al estado deguerra, la publicación de El Salvadoreño tuvo que suspenderse; a pesar de ello, los números existentes permiten el estudio de algunos de los meses que comprenden una época convulsa en Centroamérica desde la perspectiva de uno de los Estados más importantes del área.

En suma, el presente artículo aspira a contribuir a un mejor conocimiento de las características y aspiraciones de los grupos de poder salvadoreños en el contexto de la guerra federal, en su esfuerzo por crear una opinión pública nacional expresada en las páginas de este efímero periódico.

\section{Notas}

${ }^{1}$ Agradezco a Sajid Herrera Mena, y al personal encargado del resguardo de las Colecciones Especiales de la Biblioteca Florentino Idoate, de la Universidad Centroamericana Simeón Cañas en El Salvador, la digitalización y envío de El Salvadoreño. También agradezco la lectura y sugerencias del profesor Herrera Mena a una versión previa de este trabajo. Asimismo, un borrador de este texto fue presentado en el III Congreso de Historia Intelectual de América Latina, celebrado en el Colegio de México en noviembre del 2016 (Ciudad de México, 9 de noviembre de 2016), y en la sesión del 26 de enero de 2017 del Seminario Permanente de Historia de Chiapas y Centroamérica, CESMECA-CIESAS-SuresteCIMSUR, San Cristóbal de las Casas, Chiapas.

${ }^{2}$ Texto citado por Florencia Gutiérrez en "La disputa por las calles, el pueblo y la espontaneidad", documento comentado en el seminario interinstitucional de Historia Política del Instituto Mora, el 7 de noviembre de 2017, y que esta autora retoma de Gantús y Salmerón (2014: 14). ${ }^{3}$ Diferencia entre pueblo y público en la obra de Gerald Mac Gowan. Citado por Laurence Coudart en el texto: "La libertad de imprenta en las Memorias ministeriales: comunicación gubernativa, dinámicas legales y periodísticas (México, 1821-1867)”, p. 2., comentado el 23 de enero de 2018 en el seminario interinstitucional de historia política del Instituto Mora (Ciudad de México).

${ }^{4}$ El Salvadoreño, "Relaciones", 12 de junio de 1828.

5 Juan José de Aycinena fue el jefe de la familia más acaudalada y poderosa de Centroamérica, jugó un papel clave en la 
historia del istmo ocupando cargos de influencia en la Iglesia y el Estado. Se opuso a la Federación Centroamericana y una vez conseguido ese objetivo se dedicó a forjar en Guatemala una sociedad más conservadora. Manuel Francisco Pavón Aycinena, sobrino de Juan José, fue un influyente político conservador guatemalteco durante el régimen de Rafael Carrera (1839-1866).

${ }^{6}$ El Salvadoreño, "Diplomacia", 15 de junio de 1828.

${ }^{7}$ El Salvadoreño, "Verdadero patriotismo", 20 de julio de 1828.

${ }^{8}$ El Salvadoreño, 9 de septiembre de 1828.

${ }^{9}$ El Salvadoreño, 14 de diciembre de 1828.

${ }^{10}$ El Salvadoreño, 9 de septiembre de 1828.

${ }^{11}$ El Salvadoreño, "Origen de la revolución actual", 5 de junio de 1828.

${ }^{12}$ Decreto del 5 de diciembre de 1827 dado por Arce con el objeto de convocar a un nuevo constituyente para la república centroamericana.

${ }^{13}$ El Salvadoreño, "Origen de la revolución actual", 5 de junio de 1828.

${ }^{14}$ El Salvadoreño, "Objetos de esta revolución", 5 de junio de 1828.

${ }^{15}$ El Salvadoreño, "Concluye el artículo sobre los objetos de la revolución actual", 8 de junio de 1828.

${ }^{16}$ El Salvadoreño, "Tribunales de policía", 28 de diciembre de 1828 .

${ }^{17}$ De hecho, la élite liberal san salvadoreña hizo de su oposición a la anexión al imperio mexicano una victoria moral sobre Guatemala (López Bernal, 2011: 74).

${ }^{18}$ El Salvadoreño, "Centro América. San Salvador", 10 de julio de 1828.

${ }^{19}$ El Salvadoreño, "América. Centro América", 6 de julio de 1828.

${ }^{20}$ El Salvadoreño, "De la autoridad del pueblo bajo el sistema representativo federal", 5 de junio de 1828.

${ }^{21}$ El Salvadoreño, "Elecciones populares", 21 de diciembre de 1828

${ }^{22}$ El Salvadoreño, "Breves reflexiones sobre los artículos contenidos en las anteriores instrucciones", 15 de junio de 1828 .

23 El Salvadoreño, "2do. Asesinato, ejecutado por el chapetón Vicente Domínguez de orden de las familias de Guatemala, 3 de julio de 1828.

24 El Salvadoreño, "2do. Asesinato, ejecutado por el chapetón Vicente Domínguez de orden de las familias de Guatemala", 3 de julio de 1828. En cursivas en el original.

${ }^{25}$ El Salvadoreño, "Centro-América", 27 de julio de 1828.

${ }^{26}$ El Salvadoreño, "Centro-América. Guatemala", 7 de agosto de 1828.

${ }^{27}$ En enero de 1827.

${ }^{28}$ Dada en 1827 a raíz de la conspiración de Arenas.

${ }^{29}$ El Salvadoreño, "Centro-América. Guatemala", 10 de agosto de 1828.

${ }^{30}$ El Salvadoreño, "Noticias Extranjeras. Elecciones de presidente y vicepresidente de la república mexicana", 30 de octubre de 1828.

31 El Salvadoreño, "Centro-América. Guatemala", 7 de agosto de 1828.

${ }^{32}$ El Salvadoreño, "Verdadero Patriotismo, 20 de julio de 1828.

${ }^{33}$ El Salvadoreño, 9 de septiembre de 1828.

${ }^{34}$ La libertad de imprenta se estableció en la constitución salvadoreña de 1824.

${ }^{35}$ El Salvadoreño, "De la imprenta", 3 de julio de 1828.

${ }^{36}$ El Salvadoreño, "Educación", 6 de julio de 1828. Artículo e ideas retomadas del Correo Literario y Político de Londres.

${ }^{37}$ El Salvadoreño, "Educación”, 17 de julio de 1828.

${ }^{38}$ El Salvadoreño, "América. Ventajas de la independencia", 27 de julio de 1828.

39 Ver cita número 7 tomada de El Salvadoreño correspondiente al 9 de septiembre de 1828 .

\section{Referencias}

Barrios y Barrios, Catalina (2003). Estudio histórico del periodismo guatemalteco (época colonial y siglo XIX). Guatemala: Editorial Universitaria.

Belaubre, Christopher (2014). "Opinión pública". En Jordana Dym y Sajid Herrera (coords.). Centroamérica durante las revoluciones atlánticas: el vocabulario político, 1750-1850. San Salvador: IEESFORD Editores, pp. 181197.

Bonilla Bonilla, A. (1999). Ideas económicas en la Centroamérica ilustrada 1793-1838. El Salvador: FLACSO. Chandler, David Lee (1988). Juan José de Aycinena. Idealista conservador de la Guatemala del siglo XIX. Antigua, Guatemala: Centro de Investigaciones Regionales de Mesoamérica. 
Claps Arenas, María Eugenia (1999). La producción hemerográfica que los españoles exiliados en Londres dedicaron a Hispanoamérica. El caso de México (18241827). Tesis de maestría, UNAM, México.

Dym, Jordana y Sajid Herrera (coords.) (2014). Centroamérica durante las revoluciones atlánticas: el vocabulario político, 1750-1850. San Salvador: IEESFORD Editores.

Fernández Sebastián, Javier (2009). Diccionario político y social del mundo iberoamericano. La era de las revoluciones, 1750-1850. Madrid: Fundación Carolina, Sociedad Estatal de Conmemoraciones Culturales, Centro de Estudios Políticos y Constitucionales.

Gantús, Fausta y Alicia Salmerón (2014). Prensa y elecciones. México: Instituto Mora, IFE.

Gutiérrez Álvarez, Coralia (2014). "Pueblo/Pueblos”. En Jordana Dym y Sajid Herrera (coords.). Centroamérica durante las revoluciones atlánticas: el vocabulario político, 1750-1850. San Salvador: IEESFORD Editores, pp. 249-265.

Herrera Mena, Sajid (2005). "La invención liberal de la identidad estatal salvadoreña 1824-1839”. En Estudios Centroamericanos. Revista de Extensión Cultural de la Universidad Centroamericana "José Simeón Cañas", LX(684): 913-937.

Herrera Mena, Sajid (2011). "Las facciones políticas en El Salvador del siglo XIX”. En Xiomara Avendaño (coord). Historia electoral en Centroamérica. El Salvador: Lea Grupo Editorial, pp. 177- 215.

López Bernal, C.G. (2011). "De intendencia a Estado nacional: un balance de la historia política salvadoreña, 1786-1890". En Carlos Gregorio López Bernal (comp.), Poder, actores sociales y conflictividad. El Salvador, 1786-1972. San Salvador: Dirección Nacional de Investigaciones en Cultura y Arte de la Secretaria de Cultura de la Presidencia, pp. 60-90.

López Vallecillos, Ítalo (1987). El periodismo en El Salvador. Bosquejo histórico documental, precedido de apuntes sobre la prensa colonial hispanoamericana. San Salvador: UCA Editores.

Mac Gowan, Gerald (1978). Prensa y poder, 1854-1857, La revolución de Ayutla, El Congreso Constituyente. México: El Colegio de México.
Palti, Elías (2008). "Tres etapas de la prensa política mexicana en el siglo XIX: el publicista y los orígenes del intelectual mexicano". En Carlos Altamirano y Jorge Myers (coords.), Historia de los intelectuales en América Latina I. La ciudad letrada, de la conquista al modernismo. Madrid: Katz Editores, pp. 227-241.

Taracena Arriola, Arturo (1995). "Nación y república en Centroamérica (1821-1865)”. En Arturo Taracena y Jean Piel (coords), Identidades nacionales y estado moderno en Centroamérica. San José, Costa Rica: CIHAC Editorial de la Universidad de Costa Rica, pp. 30- 60.

Taracena Arriola, Arturo (2010). "Algunos oficiales extranjeros que combatieron en las guerras civiles de la República Federal Centroamericana, 1826-1839". En Boletín AFEHC, 46: julio-septiembre. Disponible en: http://www.afehc-historia-centroamerica.org [consultado el 30 de mayo de 2016].

Taracena Arriola, Arturo (2015a). "Presentación". En Arturo Taracena (ed). La primera guerra federal centroamericana, 1826-1829. Nacióny estados, republicanismo y violencia. Guatemala: URL, Editorial Cara Parens, pp. IX-XXIV.

Taracena Arriola, Arturo (2015b). "La mirada de tres actores guatemaltecos sobre la Guerra Federal de 1826-1829: Montúfar y Coronado, Córdova y García Granados. Reflexiones metodológicas sobre un conflicto armado". En Arturo Taracena (ed). La primera guerra federal centroamericana, 1826-1829. Nación y estados, republicanismo y violencia. Guatemala: URL. Editorial Cara Parens, pp. 55- 86.

Taracena Arriola, L.P. (2015). “iGuerra estatal o guerra de ciudades? Movilización militar, recaudación y discurso político, 1826-1829”. En Arturo Taracena (ed). La primera guerra federal centroamericana, 1826-1829. Nación y estados, republicanismo y violencia. Guatemala: URL, Cara Parens, pp. 1-54.

Tenorio Góchez, Ruth (2006). Periódicos y cultura impresa en El Salvador (1824-1850): cuân rápidos pasos da este estado hacia la cultura europea. Tesis de doctorado, The Ohio State University, Ohio, Estados Unidos.

Vega Jiménez, Patricia (1995). De la imprenta al periodismo. Los inicios de la comunicación impresa en Costa Rica, 18211850. San José, Costa Rica: Editorial Porvenir. 
Foto 1. Portada de El Salvadoreño, núm. 1

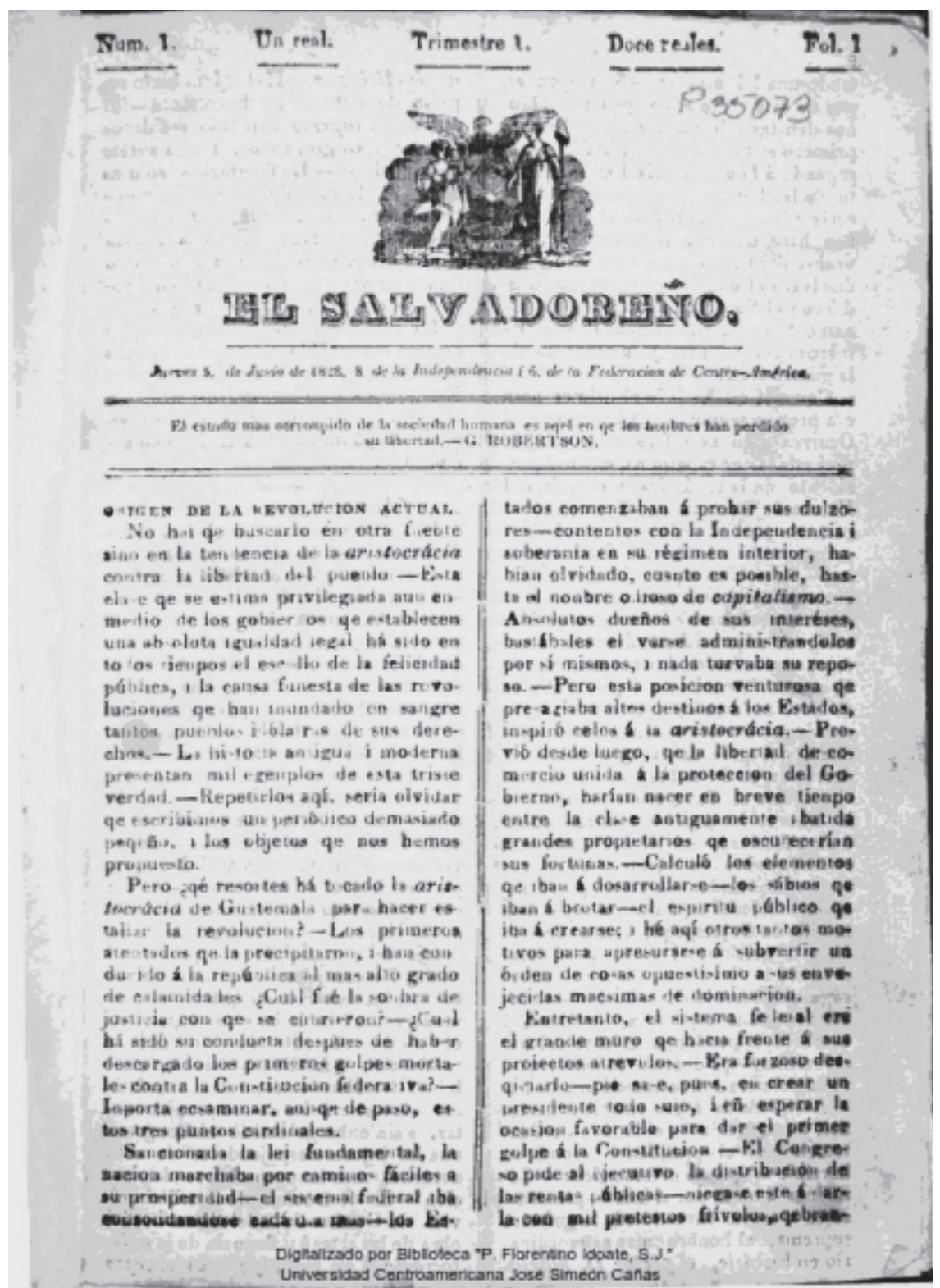

Fuente: este periódico forma parte del acervo de las Colecciones Especiales de la Biblioteca Florentino Idoate, de la Universidad Centroamericana Simeón Cañas en El Salvador. La digitalización fue facilitada por el personal de la biblioteca con la autorización del Dr. Sajid Herrera Mena. 